Z. vergl. Physiologie 70, 196-209 (1970)

(C) by Springer-Verlag 1970

\title{
Thermoregulation and Heterothermy in Some of the Smaller Flying Foxes (Megachiroptera) of New Guinea
}

\author{
George A. Bartholomew \\ Department of Zoology, University of California, Los Angeles, California \\ WILLIAM R. DAWSON \\ Department of Zoology, University of Michigan, Ann Arbor, Michigan! \\ ROBERT C. LASIEWSKI \\ Department of Zoology, University of California, Los Angeles, California
}

Received July 31, 1970

\begin{abstract}
Summary. Body temperature, heterothermy, oxygen consumption, heart rate, and evaporative water loss were studied in four species of flying foxes (Megachiroptera), Dobsonia minor, Nyctimene major, Nyctimene albiventer, and Paranyctimene raptor, from the vicinity of Madang on the north coast of New Guinea.

The thermoregulatory response of $D$. minor resembled that of most other placental mammals weighing 80 to $100 \mathrm{~g}$. Body temperatures were relatively stable at ambient temperatures between 5 and $34^{\circ}$. The mean oxygen consumption at rest between 30 and $35^{\circ}$ was $1.26 \mathrm{cc} \mathrm{O}_{2}(\mathrm{~g} \cdot \mathrm{hr})^{-1}$. At ambient temperatures between 5 and $35^{\circ}$ evaporative water loss averaged $4.5 \mathrm{mg}(\mathrm{g} \cdot \mathrm{hr})^{-1}$ and increased sharply at higher temperatures. When subjected to heat stress the animals panted, salivated, and licked the wings, belly, and uropatagium. At temperatures above $38^{\circ}$ the ratio of heat lost through evaporation to heat production exceeded 1. Minimal heart rates in resting animals near thermal neutrality were approximately $275 / \mathrm{min}$.

In those parameters measured, $N$. major which weighed about $80 \mathrm{~g}$ resembled D. minor.

Nyctimene albiventer and $P$. raptor weigh less than $30 \mathrm{~g}$ and are among the smallest of the flying foxes. Each shows both homeothermic and heterothermic patterns of response. At an ambient temperature of $35^{\circ}$ the minimal oxygen consumption of homeothermic $N$. albiventer and $P$. raptor were 1.43 and $1.38 \mathrm{cc} \mathrm{O}_{2}$ $(\mathrm{g} \cdot \mathrm{hr})^{-1}$, respectively. Oxygen consumption of homeothermic $N$. albiventer at $25^{\circ}$, $2.59 \mathrm{cc} \mathrm{O}_{2}(\mathrm{~g} \cdot \mathrm{hr})^{-1}$, was almost quadruple that of torpid animals at the same temperature. During the daytime both $N$. albiventer and $P$. raptor characteristically allowed their body temperatures to fall to near $25^{\circ}$. Both readily aroused from the hypothermic state through physiological means. Heart rates of homeothermic $N$. albiventer resting at $35^{\circ}$ ranged from 312 to $326 / \mathrm{min}$ while those of animals torpid at $25^{\circ}$ were 88 to $96 / \mathrm{min}$.

The capacity for heterothermy has not previously been demonstrated in any members of the Megachiroptera, but our data indicate that it can occur on a daily basis in $N$. albiventer and $P$. raptor. This capacity appears to be related to size since it occurs in none of the larger flying foxes so far studied.
\end{abstract}


The data presently available indicate that the relation of body weight to standard metabolism in the Megachiroptera is similar to that of the other placental mammals. In the species we studied, thermal conductances were higher, and heart rates, lower than predicted for mammals of their sizes.

\section{Introduction}

Bats are by far the most numerous of the mammals indigenous to New Guinea. A number of them belong to the suborder Megachiroptera, members of which are widely distributed through the tropical and subtropical parts of the Eastern Hemisphere. The Megachiroptera have been separated from the other suborder of bats, the Microchiroptera, since at the least the early Eocene (Jepson, 1966). The two suborders differ in many respects. The Microchiroptera are predominantly insectivorous, often show daily or seasonal patterns of torpor, and depend on echolocation more than on vision for orientation. The Megachiroptera feed almost exclusively on plants, depend on vision rather than hearing for orientation (one cave dwelling genus, Rousettus, can use low frequency clicks for echolocation), and have not hitherto been shown to experience heterothermy. As the names of the two taxa imply, most members of the Microchiroptera are small, whereas most of the Megachiroptera are much larger, although considerable overlap in size exists between the two groups.

In contrast to the situation in microchiropterans, the physiology of megachiropterans has received little attention. Detailed information on thermal responses is available for representatives of only two genera, Rousettus and Pteropus (see Kulzer, 1963a, b; Bartholomew et al., 1964, for references). These animals are relatively large and both types are excellent thermoregulators, which never, as far as known, undergo marked hypothermia. The physiology of small megachiropterans remains virtually unstudied. We therefore made a special effort during the 1969 Alpha Helix Expedition to New Guinea to examine some of the physiological responses of small and medium-sized members of this group to temperature. We were successful in obtaining results for Dobsonia minor, Nyctimene major, Nyctimene albiventer, and Paranyctimene raptor, the latter two of which are among the smallest of the Megachiroptera.

\section{Materials and Methods}

The experimental animals were captured in mist nets set in a patch of primary rain forest near our camp on the coast $32 \mathrm{~km}$ north of Madang (Lat., $5^{\circ} 2^{\prime} \mathrm{S}$ ), Territory of Papua and New Guinea. They were housed in wire mesh cages in an open-sided, outdoor shelter. The cage for the Dobsonia measured $46 \times 46 \times$ $184 \mathrm{~cm}$ and that for the $N$ yctimene and Paranyctimene, $46 \times 46 \times 92 \mathrm{~cm}$. The animals all fed readily on papayas, bananas, and a nutrient broth of prepared baby food to 
which sucrose was added. Dobsonia minor and Nyctimene major thrived in captivity, but Nyctimene albiventer and Paranyctimene raptor were more fragile and their condition tended to decline after a week. Individuals of the latter two species were therefore studied within the first two or three days after capture.

The Megachiroptera are primarily nocturnal. Aside from some determinations of body temperature made at night, all measurements were made during the daytime on animals that had been under stable conditions of temperature, light and humidity for at least $90 \mathrm{~min}$ and often for 4 or more hours. Although the bats struggled vigorously when handled, they were remarkably docile during the periods of measurement and often hung quietly for several hours.

Oxygen consumption and evaporative water loss were measured with an open circuit system with the methods described by Dawson and Fisher (1969). The circuit included a Beckman F3 paramagnetic oxygen analyzer and absorbants for remoring $\mathrm{CO}_{2}$ and water both upstream and downstream from the respirometer chamber. Total evaporative water loss was determined from the increase in weight of the down stream dessicant during a 15 or $30 \mathrm{~min}$ interval. The respirometer chamber consisted of a transparent plastic (lucite or perspex) cylinder $30 \mathrm{~cm}$ long and $10 \mathrm{~cm}$ in diameter. The bottom was sealed and equipped with a snugly fitted polyethylene cup containing mineral oil to cover urine or feces voided during the period of measurement. The top of the cylinder was sealed with a rubber stopper fitted with airtight ports for a thermocouple and for incurrent and excurrent air. The experimental animal was placed in a cylindrical container of wire mesh $(1 / 4$ inch mesh on sides; $1 / 2$ inch mesh top and bottom) measuring $8.5 \times 17 \mathrm{om}$. This containercage was then inserted in the lucite cylinder and the system was placed in a controlled temperature cabinet where it was allowed to come to equilibrium at the desired temperature. The animals hung head-downward from the top of the wire mesh cylinder. Air flow was held constant during each experiment but the rate was varied from 300 to $2000 \mathrm{cc} / \mathrm{min}$ depending on the size of the animal and its rate of water loss. By using different rates of air flow, the ambient water vapor pressure was maintained between 6 and $20 \mathrm{~mm} \mathrm{Hg}$, as calculated with the equation of Lasiewski et al. (1966).

All gas volumes are converted to STP, and all temperatures are expressed in ${ }^{\circ} \mathrm{C}$.

Ambient temperatures were controlled to within $0.3^{\circ}$ with a constant temperature cabinet and measured to within $0.1^{\circ}$ with 30 gauge copper-constantan thermocouples connected to a 12-channel Honeywell Electronik 16 recorder. Body temperatures were measured rectally at a depth of $2.5 \mathrm{~cm}$ with a 30 gauge thermocouple sheathed in a polyethylene tube.

Heart rate was obtained from electrocardiograms registered on a HewlettPackard 180/AR Oscilloscope used in conjunction with a Grass P-8 a.c. preamplifier and a Grass AM 4 Audiomonitor. The electrocardiographic leads were attached subcutaneously on each shoulder. A third lead attached to the sacral region served as a ground. During measurements of heart rate the bats hung quietly in a wire cage in the dark at an ambient temperature of $31-32^{\circ}$.

The behavioral responses of the bats were observed through an insulated window in the temperature cabinet.

\section{Results}

Our study was based on $9 D$. minor, $13 P$. raptor, $18 N$. albiventer, and $2 N$. major. Their mean body weights were $87.0 \pm 9.3$ s.d., $21.3 \pm 2.8$ s.d., $28.2 \pm 2.5$ s.d., and 79.5 grams, respectively. 


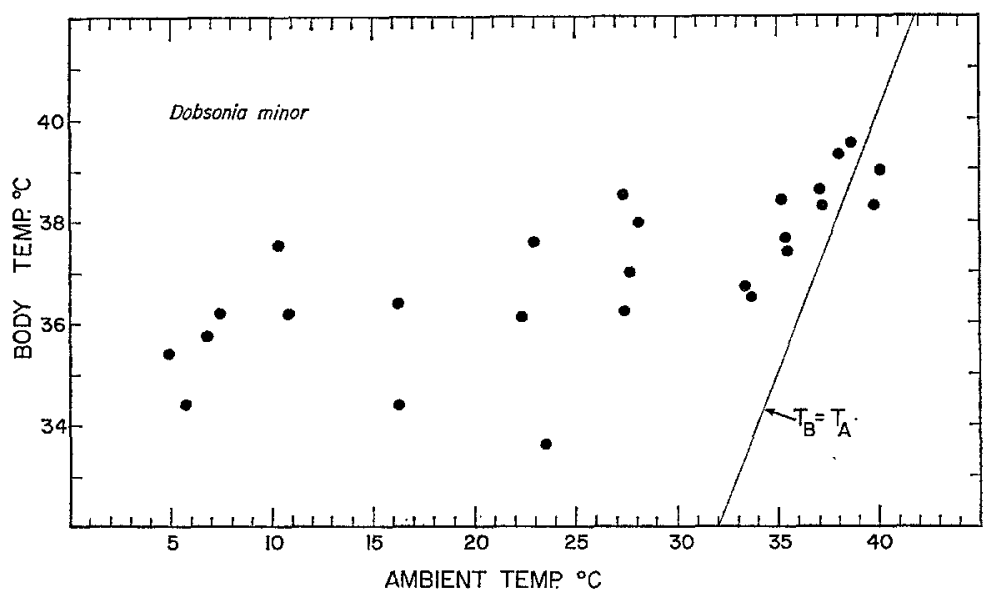

Fig. 1. The relation of body temperature of Dobsonia minor to ambient temperature at the end of 90 to 120 min periods of measurement of oxygen consumption. Each value at a given $T_{\mathcal{A}}$ is from a different animal

\section{Dobsonia minor}

Body Temperature. The thermoregulatory performance of $D$. minor resembled that found in most other placental mammals weighing 80 to $100 \mathrm{~g}$. Body temperatures remained relatively stable during exposures of 90 to $120 \mathrm{~min}$ to ambient temperatures between 5 and $34^{\circ}$ (Fig. 1). Some hyperthermia was evident at ambient temperatures above $35^{\circ}$. The bats maintained body temperature below ambient at $40^{\circ}$ and a water vapor pressure of 17 to $20 \mathrm{~mm} \mathrm{Hg}$ (see section on evaporative cooling).

As in most nocturnal mammals, in the absence of temperature stress the body temperatures of $D$. minor were higher at night than during the day.

Oxygen Consumption. The relation between oxygen consumption and ambient temperature in $D$. minor generally conforms to the usual homeothermic pattern (Fig. 2). Our data do not indicate any clearly defined zone of thermal neutrality, but suggest the existence of a thermal neutral point near $34^{\circ}$. The mean oxygen consumption of 6 resting animals measured between 30 and $35.5^{\circ}$ was $1.26 \pm 0.12$ s.d. cc $\mathrm{O}_{2}(\mathrm{~g} \cdot \mathrm{hr})^{-1}$. Below $25^{\circ} \mathrm{O}_{2}$ consumption was inversely related to ambient temperature. Above the thermal neutral point oxygen consumption increased slowly with increasing ambient temperature reflecting the energetic cost of enhanced evaporative cooling, and the effects of hyperthermia.

Evaporative Water Loss. At ambient temperatures between 5 and $35^{\circ}$ evaporative water loss showed virtually no thermal dependence and had a mean value of $4.5 \pm 1.3$ s.d. $\mathrm{mg}(\mathrm{g} \cdot \mathrm{hr})^{-1}$. At temperatures of $37^{\circ}$ and 


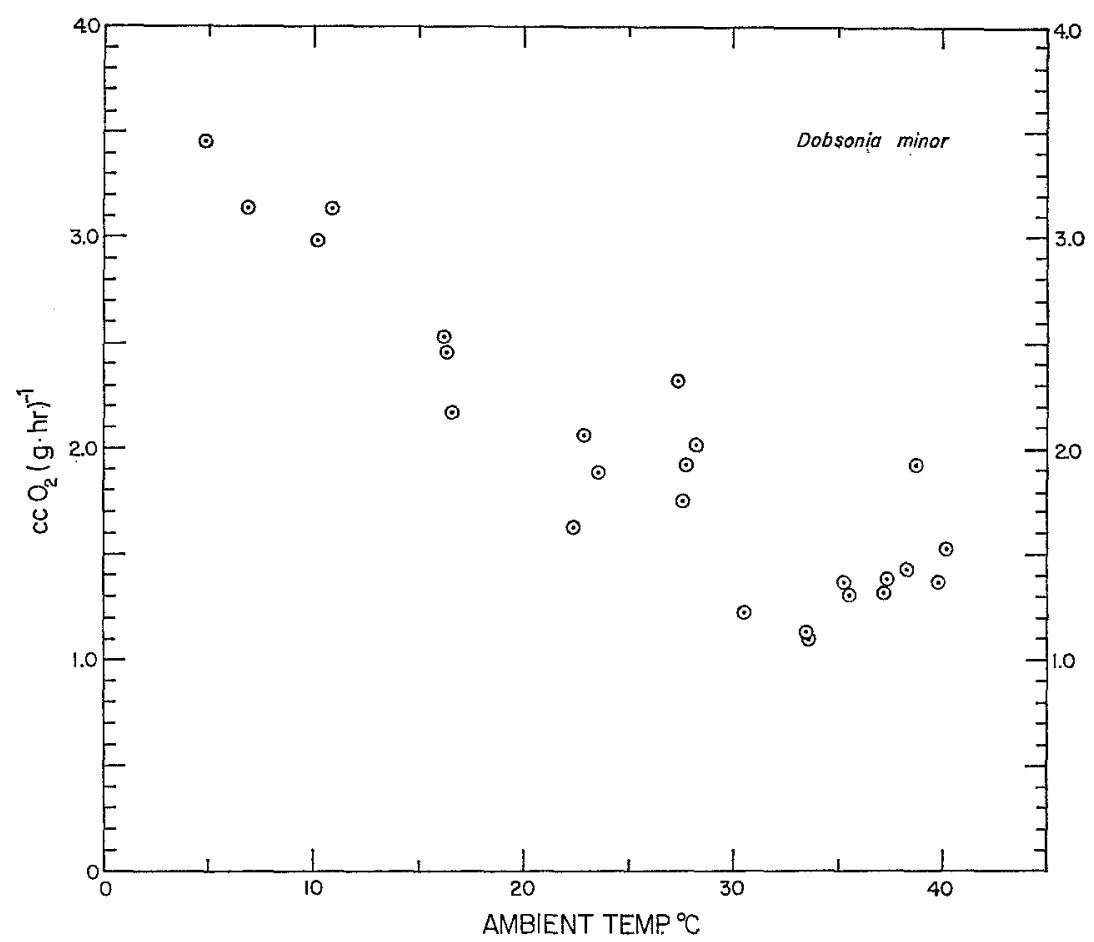

Fig. 2. The relation of minimal oxygen consumption to ambient temperature in 7 Dobsonia minor with a mean weight of $87 \mathrm{~g}$

above the bats engaged in panting, salivation, and licking (see section on behavior) and evaporative water loss increased sharply (Fig. 3).

Since evaporation involves loss of heat, it is of interest to examine the ratio of calories lost through evaporation to calories produced by oxidative metabolism, i.e., evaporative water loss (EWL) divided by heat production (HP). When this ratio (EWL/HP) is less than 1 , heat loss through evaporation is less than heat production and some portion of the metabolic heat is being lost via conduction, convection and radiation, or stored. Conversely when EWL/HP exceeds 1 all of the metabolic heat plus some of the heat gained from the environment can be dissipated through evaporation. The EWL/HP ratio for $D$. minor increased with ambient temperature (Fig. 4) and exceeded unity at temperatures above $38^{\circ}$. At the highest temperature studied, approximately $40^{\circ}$, the animals dissipated far more heat through evaporative cooling than they produced metabolically, enabling them to maintain body temperature below that of the environment (Figs. 1 and 4). 


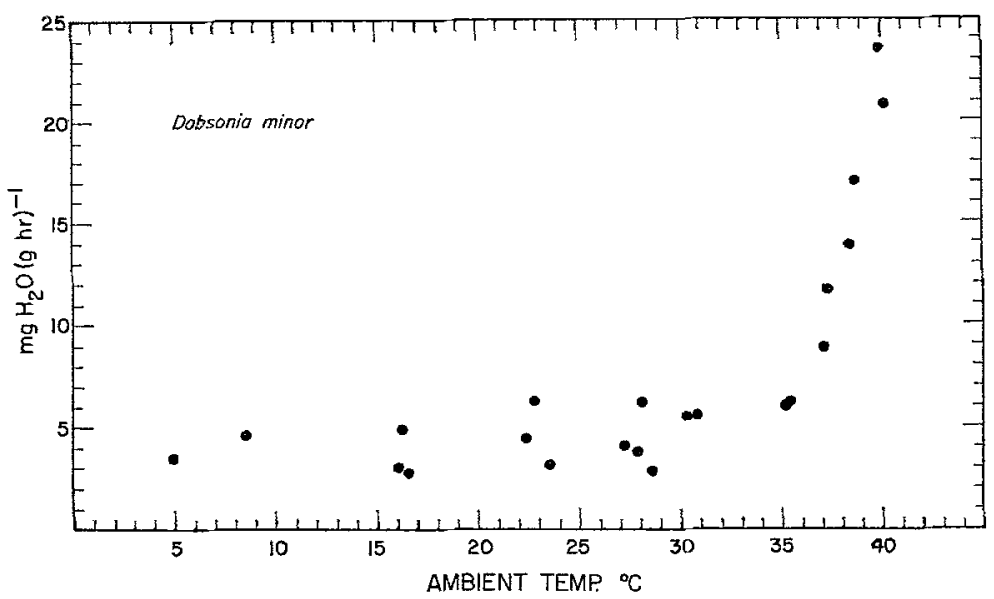

Fig. 3. Evaporative water loss in relation to ambient temperature in Dobsonia minor

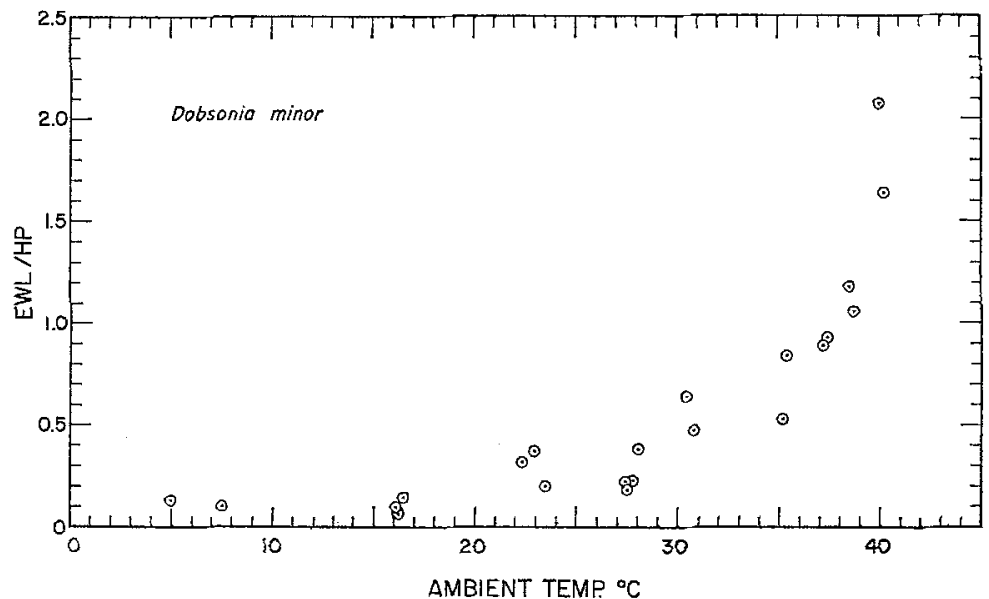

Fig. 4. The ratio of calories lost by evaporation (EWL) to calories produced by oxidation (HP) in relation to ambient temperature in Dobsonia minor. Data converted to caloric terms by assuming $1 \mathrm{mg} \mathrm{H} \mathrm{H}_{2} \mathrm{O}=0.58 \mathrm{cal}$ and $1 \mathrm{cc} \mathrm{O}_{2}=4.8 \mathrm{cal}$

Weight-specific Conductance. When an animal has a constant body temperature, heat loss and heat production (HP) are necessarily equal, and if $T_{B}$ is higher than $T_{A}$, an estimate of heat flow (often referred to as thermal conductance) can be calculated from the formula, $C=$ $\frac{H P}{T_{B}-T_{A}}$. From Fig. 5 it can be seen that total conductance decreased in a curvilinear manner with decreasing ambient temperatures below 


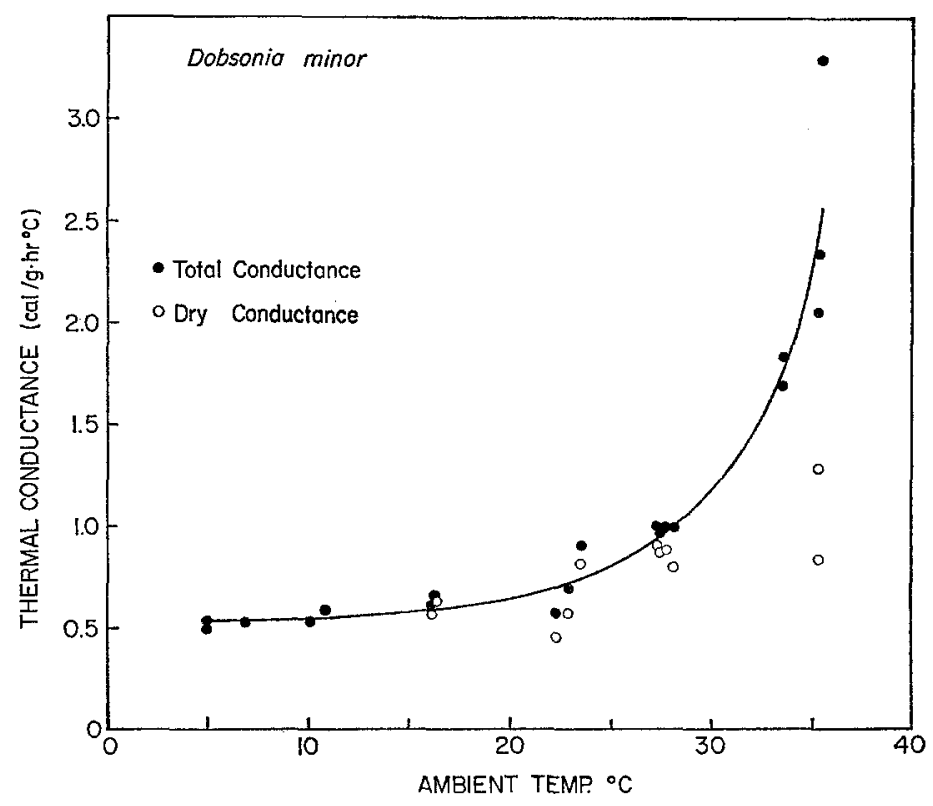

Fig. 5. The relation of thermal conductance to ambient temperature. See legend of Fig. 4 for caloric conversions

thermal neutrality, and did not reach its minimum level until the temperature was near $15^{\circ}$. The difference between total conductance and dry conductance $\frac{\mathrm{HP}-\mathrm{EWL}}{T_{B}-T_{A}}$ increased with temperature above $20^{\circ}$.

Heart Rate. The mean hearts rates of $3 \mathrm{D}$. minor resting in the dark at $35^{\circ}$ for 3 to 8 hours, were $275 \pm 8$ s.d., $275 \pm 22$ s.d., and $278 \pm 7$ s.d. $\min ^{-1}$.

Behavioral Responses. When D. minor were at rest at a temperature near thermoneutrality, they characteristically enshrouded the body in their wings. At low temperatures they shivered vigorously and enclosed not only the body, but also most of the head, with the wings, sometimes while hanging by one leg and putting the other leg under the wings. In this posture the uropatagium was folded around the leg by which they remained suspended and maximal insulation was obtained. During heat stress the wings were held out from the sides of the body, exposing the head and ventral surfaces to air movements. Respiration became heavier and more rapid but its irregularity made characterization of breathing rate difficult.

The bats responded to heat stress by panting with open mouth and extruded tongue; they salivated profusely and licked the uropatagium, 


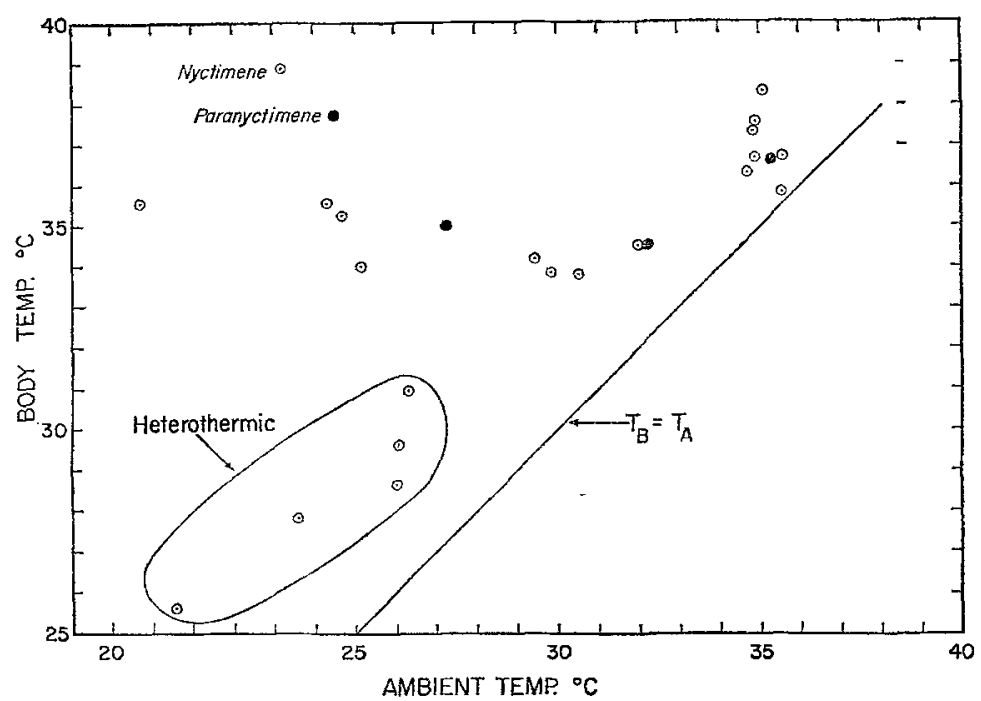

Fig. 6. The relation of body temperatures of $N$. albiventer and $P$, raptor to ambient temperature at the end of 90 to 120 min periods of measurement of oxygen consumption. In any given $2^{\circ}$ interval of ambient temperature each point represents a different individual

the venter, and both the inner and outer surfaces of the wings, especially the digits. In addition, the blood vessels of the wings and uropatagium became engorged, and the testes, which are usually abdominal, became scrotal. However, no wing shuffling or wing fluttering was seen at any time in response to heat.

\section{Nyctimene and Paranyctimene}

Aside from some limited information on Syconycteris (Bartholomew et al., 1964) we are unaware of any data on thermoregulation or any demonstration of daily torpor in small megachiropterans.

Body temperature. N. albiventer and $P$. raptor are very similar in appearance, and in captivity showed similar patterns of behavior. Their thermoregulatory responses fall into two contrasting patterns, one characteristic of small homeothermic mammals and the other, of heterothermic mammals.

Both the homeothermic and heterothermic patterns of response were apparent in the body temperatures taken at the end of the 90 to $120 \mathrm{~min}$ periods of measurement of oxygen consumption (Fig. 6). Most of the animals remained homeothermic but some allowed body temperature to fall. 


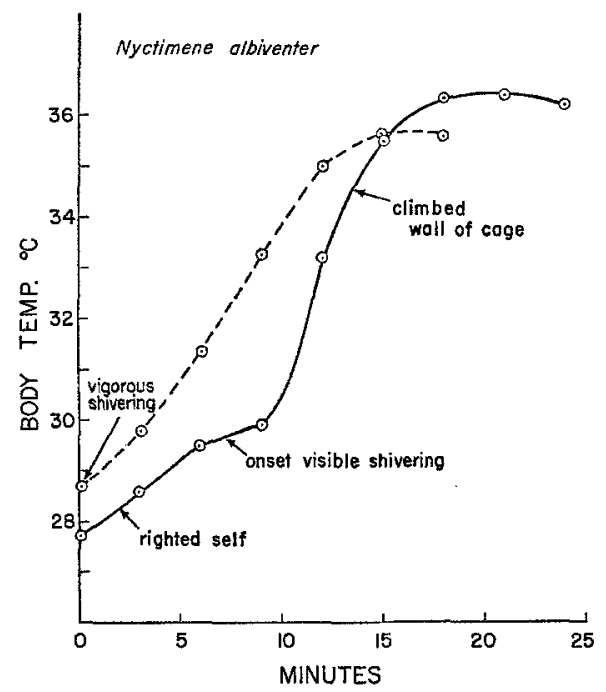

Fig. 7. The course of body temperature during arousal from a hypothermic state in two $N$. albiventer. Ambient temperatures, 24.2 to $26.1^{\circ}$

Both $N$. albiventer and $P$. raptor could readily arouse from the hypothermic state through physiological means. The rate of increase in body temperature of $N$. albiventer was approximately half a degree per minute (Fig. 7). During arousal the animals shivered vigorously. Even at body temperatures between 25 and $30^{\circ}$ they righted themselves, climbed vigorously, and vocalized loudly.

We further examined the heterothermic pattern by undertaking a series of simple experiments that began at approximately $08,00 \mathrm{hr}$ local time. In these experiments $11 N$.albiventer and $9 P$.raptor, freshly captured and in good condition, were placed in a darkened temperature cabinet at an ambient temperature of $25^{\circ}$ and left undisturbed for $4 \mathrm{hr}$. We also subjected the much larger species, $N$. major, to the same procedure. Of the $11 \mathrm{~N}$. albiventer, 7 showed a decline in body temperature (mean 5.4 $4^{\circ}$, range $3.8-7.7^{\circ}$ ); 3 showed no change, and one increased its body temperature by $1.3^{\circ}$. All of the $9 P$. raptor underwent a decline in body temperature (mean $3.6^{\circ}$, range 1.1-9.9 ${ }^{\circ}$. Neither of the Nyctimene major, which are about the same size as Dobsonia showed any decline in body temperature.

Oxygen Consumption. At an ambient temperature of $35^{\circ}$ the minimal oxygen consumptions of resting $N$.albiventer and P. raptor were 1.43 and $1.38 \mathrm{cc} \mathrm{O}_{2}(\mathrm{~g} \cdot \mathrm{hr})^{-1}$ respectively. Oxygen consumption of homeothermic $N$. albiventer at $25^{\circ}$ [mean $2.59 \mathrm{cc} \mathrm{O}_{2}(\mathrm{~g} \cdot \mathrm{hr})^{-1}$ ] was almost quadruple that, 
Table 1. Oxygen consumption in Nyctimene and Paranyctimene during homeothermy and heterothermy

\begin{tabular}{|c|c|c|c|c|c|}
\hline Species & $N$ & $\begin{array}{l}\text { Thermoregulatory } \\
\text { state }\end{array}$ & $T_{A}$ & $T_{B}$ & $\operatorname{cc} \mathrm{O}_{2}(\mathrm{~g} \cdot \mathrm{h})^{-1}$ \\
\hline N. albiventer & 6 & Homeothermic & $35^{\circ}$ & $35.8-37.6^{\circ}$ & $1.43 \pm 0.24$ s. d. \\
\hline N. albiventer & 2 & Homeothermic & $25^{\circ}$ & $35.8-36.1^{\circ}$ & 2.59 \\
\hline N. albiventer & 4 & Heterothermic & $25^{\circ}$ & $27.8-29.6^{\circ}$ & $0.67 \pm 0.17$ s. d. \\
\hline$P$, raptor & 2 & Homeothermic & $35^{\circ}$ & $34.5-36.7^{\circ}$ & 1.38 \\
\hline
\end{tabular}

$0.67 \mathrm{cc} \mathrm{O}_{2}(\mathrm{~g} \cdot \mathrm{hr})^{-1}$, of torpid individuals at the same temperature (Table 1).

Weight-specific Conductance. Because of their marked tendency toward heterothermy it was possible to obtain only limited data on the conductance of Paranyctimene and Nyctimene. We were, however, able to make a few satisfactory determinations on homeothermic individuals below thermal neutrality. Our best estimates for $P$. raptor at $27^{\circ}$ and for $N$. albiventer at $25^{\circ}$ are $0.32 \mathrm{cc} \mathrm{O}_{2}\left(\mathrm{~g} \cdot \mathrm{hr}{ }^{\circ} \mathrm{C}\right)^{-1}$ and $0.26 \mathrm{cc} \mathrm{O}_{2}\left(\mathrm{~g} \cdot \mathrm{hr}{ }^{\circ} \mathrm{C}\right)^{-1}$, respectively.

Heart Rates. The heart rates of homeothermic $N$. albiventer resting at an ambient temperature of $35^{\circ}$ ranged from 312 to $326 / \mathrm{min}$ while those of a $N$. albiventer torpid at $25^{\circ}$ were 88 to 96 beats $/ \mathrm{min}$. We were unable to obtain heart rates from any animal that remained homeothermic at $25^{\circ}$.

Behavior at High Ambient Temperatures. The behavior of Nyctimene and Paranyctimene was as described for Dobsonia minor. No wing fluttering was observed.

\section{Discussion}

The capacity for heterothermy is one of the most distinctive features of the physiology of insectivorous Microchiroptera, but its existence has not hitherto been demonstrated in the Megachiroptera. However, our study of very small $(20-30 \mathrm{~g})$ megachiropterans indicates that heterothermy is a conspicuous part of their physiological repertoire. Indeed, our results suggest that it occurs on a daily basis in Paranyctimene minor and Nyctimene albiventer. Our observations on other very small megachiropterans from the Madang area that we maintained in captivity revealed that heterothermy also occurs in the genera Syconycteris and Macroglossus. However, the medium-sized (ca. $80 \mathrm{~g}$ ) pteropids which we studied (Dobsonia minor and Nyctimene major) persistently maintained body temperatures at a homeothermic level. The same is true of the larger flying foxes such as Rousettus (Kulzer, 1963a) and Pteropus (Robinson and Morrison, 1957; Morrison, 1959; Kulzer, $1963 \mathrm{~b}$; and Bartholomew et al., 1964). 
The energetic advantages of heterothermy in small flying foxes presumably are the same as those that have been frequently adduced for microchiropterans (see for example, Twente and Twente, 1964; McNab, 1969). In the species which we studied, oxygen consumption begins to increase at about $30^{\circ}$, which is $5^{\circ}$ above the temperatures prevailing in the habitats where these animals spend the quiescent part of their daily cycle. Moreover, the body temperatures of these animals, when in the homeothermic state, are $35^{\circ}$ or above. Thus, a significant energy saving should accrue when body temperature is allowed to fall near that of the environment. Such a decline does not immobilize the animals. Our experimental subjects could respond in a coordinated manner when disturbed, move about effectively, and even feed, at body temperatures of $25-30^{\circ}$, the temperature range characteristic of the rain forests in the Madang area.

McNab (1969) has suggested that the occurrence of heterothermy in tropical Microchiroptera is correlated with diet; nectar and fruit eating forms being effective thermoregulators, whereas insectivorous forms are apt to show heterothermy. All flying foxes, however, eat fruit and nectar and the distribution of heterothermy in the Megachiroptera appears to be related to body size rather than diet.

The two suborders of bats have been separate at least since the Eocene (Jepson, 1966), and the observed patterns of heterothermy could have evolved independently in the two groups, a situation that is consistent with the interpretation that mammalian heterothermy is a derived and highly adaptive physiological condition.

Evaporative Water Loss. Relatively few data are available on responses to high temperatures of mammals from mesic environments. It is, therefore, worthwhile to consider our results on Dobsonia minor which inhabits lowland tropical rainforests. From an ecological standpoint, these animals can afford to depend heavily on evaporative cooling for temperature regulation, because their fruit diet has a high water content. It is of interest that the Dobsonia which we studied could maintain body temperature below environmental temperature for long periods, and that the ratio of their evaporative water loss to their heat production (EWL/HP) reached 2.0 at an ambient temperature of $39.8^{\circ}$ and a vapor pressure of $20.2 \mathrm{~mm} \mathrm{Hg}$ (Fig. 5). This is an exceptionally high ratio for a small mammal. Representatives of all three of the genera studied panted, salivated, and licked their wings, venter, and uropatagium. They also experienced conspicuous vasodilatation in the wing and tail membranes, but none of them flutter their wings as Pteropus commonly does.

Weight Relative Oxygen Consumption. The data presently available suggest that the relation of body weight to standard metabolism in megachiropterans is similar to that of placental mammals of more conven- 


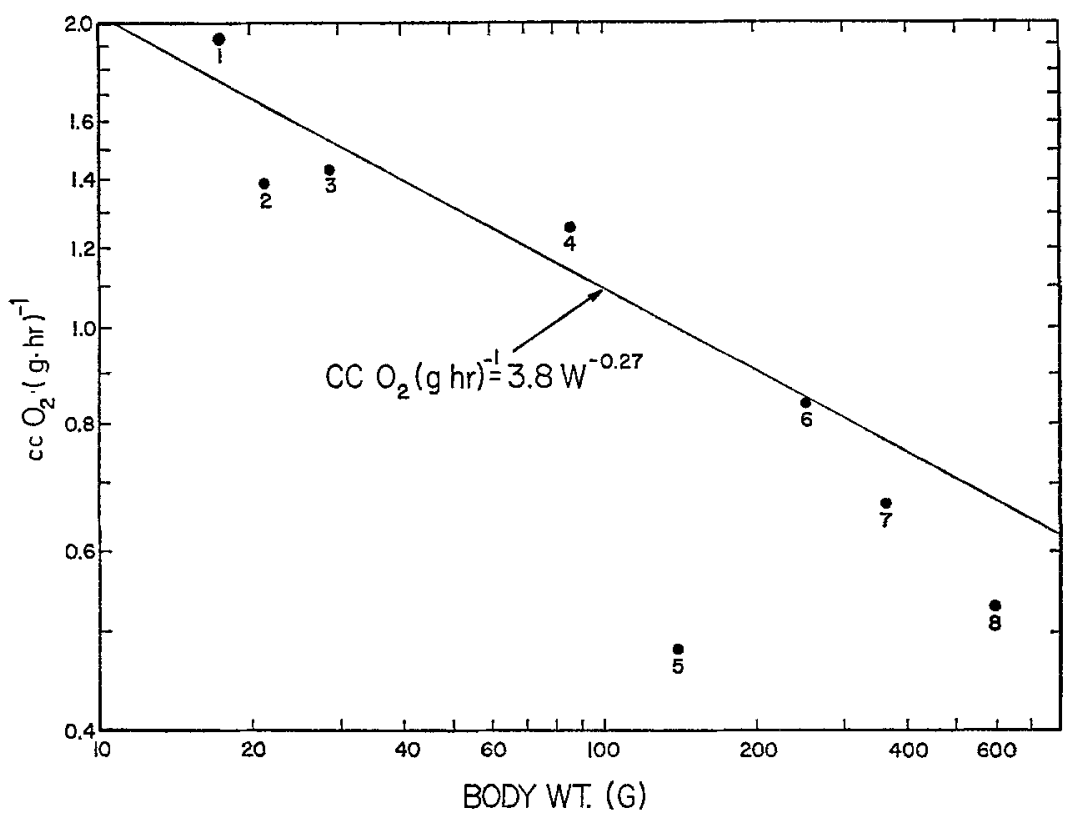

Fig. 8. The relation of standard oxygen consumption to body weight in the order Megachiroptera. Species, references, oxygen consumptions and weights are shown in Table 2 . The line shows the relationship predicted by the equation of Morrison et al. (1959), for placental mammals

Table 2. Oxygen consumption in relation to body weight in the order Megachiroptera, all animals resting at thermal neutral temperatures

\begin{tabular}{|c|c|c|c|c|}
\hline $\begin{array}{l}\text { Code } \\
\text { No. }\end{array}$ & Species & $\begin{array}{l}\mathrm{ceO}_{2} \\
(\mathrm{~g} \cdot \mathrm{h})^{-1}\end{array}$ & $\begin{array}{l}\text { wt. } \\
\text { (g) }\end{array}$ & Source \\
\hline 1 & Syconycteris australis & 1.93 & 17.5 & Bartholomew et al. (1964) \\
\hline 2 & Paranyctimene raptor & 1.38 & 21.3 & Present study \\
\hline 3 & Nyctimene albiventer & 1.43 & 28.2 & Present study \\
\hline 4 & Dobsonia minor & 1.26 & 87 & Present study \\
\hline 5 & Rousettus aegyptiacus & 0.48 & 130 & Kulzer (1963a) \\
\hline 6 & $\begin{array}{l}\text { Pteropus poliocephalus } \\
\text { (juvenile) }\end{array}$ & 0.84 & 250 & Morrison (1959) \\
\hline 7 & Pteropus scapulatus & 0.67 & 362 & Bartholomew et al. (1964) \\
\hline 8 & $\begin{array}{l}\text { Pteropus poliocephalus } \\
\text { (adult) }\end{array}$ & 0.53 & 598 & Bartholomew et al. (1964) \\
\hline
\end{tabular}

tional body shape (Table 2 and Fig. 8). The extensive areas of bare skin in wings and uropatagium apparently do not significantly affect standard metabolism. MeNab (1969) has found a more complex pattern for the Microchiroptera, with insectivorous species having basal rates that fall

14 z. vergl. Physiologie, Bd. 70 
below the expected curve and frugivorous, nectivorous, and carnivorous species having rates that equal or exceed values predicted from general metabolism-size relationships for placental mammals.

Weight-specific Conductance. The minimum total conductances of the three species studied are higher than predicted for placental mammals from the curve of Herreid and Kessel (1967) but the values for these megachiropterans are very similar to those for the microchiropterans of the same size as reported by McNab (1969).

Heart Rate and Body Weight. The observed resting heart rates in D. minor (mean wt. $87 \mathrm{~g}$ ) and $N$. albiventer (mean wt. $28 \mathrm{~g}$ ) were respectively 62 and $54 \%$ of the values predicted on the basis of weight by the allometric equation of Stahl (1967). This situation is consistent with the findings of Bartholomew et al. (1964) who found that heart rates in two much larger species of the genus Pteropus, were 51 and $59 \%$ respectively of the predicted levels.

Natural History. Not enough is known about the behavior of the flying foxes which we studied to justify more than a brief ecological interpretation of our physiological data. Dobsonia spends the daytime in caves while $P$. raptor and N. albiventer roost in trees. Daily torpor presents problems for tree-roosting bats because of danger from diurnal predators. Both $P$. raptor and $N$. albiventer are cryptically colored to a degree that is remarkable among bats. Their background color is soft yellow brown to greenish brown; the wings are covered with pale yellow, white, brown, and greenish spots which make the animals virtually invisible against the forest canopy. They hang upside down with the wings enshrouding the body. The similarity of their appearance to a dead or shriveled leaf is striking.

When in the heterothermic state with body temperatures in the mid twenties, they are capable of effective climbing and crawling and might be able to take at least limited evasive actions, but hardly enough to escape from an active predator. Presumably their cryptic coloration is their first line of defense against predation. The effectiveness of their habits and coloration in protecting them during the daytime when they are at least semi-torpid is witnessed by the very large populations of these animals which occur in the coastal forests of New Guinea.

These studies were carried out during the 1969 Alpha Helix Expedition to New Guinea and were supported in part by grants GB-5139, GB-3656, and GB-8445 from the U.S. National Science Foundation.

\section{References}

Bartholomew, G. A., Leitner, P., Nelson, J. E.: Body temperature, oxygen consumption, and heart rate in three species of Australian flying foxes. Physiol. Zool. 37, 179-198 (1964). 
Dawson, W. R., Fisher, C. D.: Responses to temperature by the Spotted Nightjar (Eurostopodus guttatus). Condor 71, 49-53 (1969).

Jepson, G. L.: Early Eocene bat from Wyoming. Science 154, 1333-1339 (1966).

Kulzer, I.: Temperaturregulation bei Flughunden der Gattung Rousettus Gray. Z. vergl. Physiol. 46, 595-618 (1963a).

- Die Regelung der Körpertemperatur beim Indischen Riesenflughund. Natur u. Mus. 93, 1-11 (1963b).

Lasiewski, R. C., Acosta, A. L., Bernstein, M. H.: Evaporative water loss in birds: I. Characteristies of the open flow method of determination, and their relation to estimates of thermogulatory ability. Comp. Biochem. Physiol. 19, 445-457 (1966).

MeNab, B. K.: The economics of temperature regulation in neotropical bats. Comp. Biochem. Physiol. 31, 227-268 (1969).

Morrison, P.: Body temperatures in some Australian mammals. I. Chiroptera. Biol. Bull. 116, 484-497 (1959).

- Ryser, F. A., Dawe, A. R.: Studies on the physiology of the masked shrew, Sorex cinereus. Physiol. Zool. 32, 256-271 (1959).

Robinson, K. W., Morrison, P. R.: The reaction to hot atmospheres of various species of Australian marsupial and placental mammals. J. cell. comp. Physiol. 49, 455-478 (1957).

Stahl, W. R.: Sealing of respiratory variables in mammals. J. appl. Physiol. 22, $453-460$ (1967).

Twente, J. W., Twente, J. A. : An hypothesis concerning the evolution of heterothermy in bats. Ann. Acad. Sci. fenn. A, IV 71 (32), 435-442 (1964).

George A. Bartholomew

Department of Zoology

University of California

Los Angeles, California 90024

U.S.A.
William R. Dawson

Department of Zoology

University of Michigan

Ann Arbor, Michigan, U.S.A.

Robert C. Lasiewski

Department of Zoology

University of California

Los Angeles, California, U.S.A. 